\title{
The Effects of Parental Depressive Symptoms, Appraisals, and Physical Punishment on Later Child Externalizing Behavior
}

\author{
Kevin A. Callender, \\ Department of Psychology, Yale University, New Haven, CT, USA \\ Sheryl L. Olson, \\ Department of Psychology, University of Michigan, Ann Arbor, MI, USA \\ Daniel E. Choe, and \\ Department of Psychology, University of Michigan, Ann Arbor, MI, USA \\ Arnold J. Sameroff \\ Department of Psychology, University of Michigan, Ann Arbor, MI, USA
}

\begin{abstract}
Examined a cognitive-behavioral pathway by which depressive symptoms in mothers and fathers increase risk for later child externalizing problem behavior via parents' appraisals of child behavior and physical discipline. Participants were 245 children (118 girls) at risk for school-age conduct problems, and their parents and teachers. Children were approximately 3 years old at Time 1 (T1) and $51 / 2$ years old at Time 2 (T2). At T1, mothers and fathers reported their depressive symptoms, perceptions of their child's reciprocal affection and responsiveness, frequency of physical punishment, and child externalizing problems. Mothers, fathers, and teachers provided ratings of externalizing behavior at $\mathrm{T} 2$. Structural equation modeling revealed that parents' negative attributions mediated positive relations between their depressive symptoms and frequency of physical punishment for both fathers and mothers. More frequent physical punishment, in turn, predicted increased child externalizing behavior at T2. In future research, transactional mechanisms underlying effects of clinical depression on child conduct problems should be explored at multiple stages of development. For parents showing depressive symptoms, restructuring distorted perceptions about their children's behavior may be an important component of intervention programs.
\end{abstract}

\section{Keywords}

Parenting; Depression; Cognitive appraisals; Child externalizing behavior; Parent gender

Children of depressed parents are at increased risk for a range of poor social, emotional, neurocognitive and behavioral outcomes (Goodman 2007), including child externalizing problems such as disruptive, aggressive, defiant and oppositional behavior (Biederman et al. 2001; Connell and Goodman 2002; Luoma et al. 2001). There are many possible

(C) Springer Science+Business Media, LLC 2011

kevin.callender@yale.edu. 
transactional pathways by which risk for these problems may be transmitted from symptomatic parents to their children (Goodman and Gotlib 1999; Kim-Cohen et al. 2005). For decades, negative parenting, which is known to elevate risk for serious and persistent antisocial behavior in children, has garnered considerable research attention (Beauchaine et al. 2005; Gershoff 2002; Johnson et al. 2006; Lynch et al. 2006; Kendziora and O'Leary 1993; Riggins-Caspers et al. 2003; Webster-Stratton and Hammond 1988).

There is strong evidence that depressive symptoms disrupt healthy parenting practices (Cummings et al. 2005; Elgar et al. 2007; Lovejoy et al. 2000). While these parenting practices are expected to be disrupted in both mothers and fathers with depressive symptoms, the existing research has primarily investigated the impact of maternal depressive symptoms. Furthermore, relatively little is known about specific mechanisms underlying this association. Some studies have suggested that this link may be partly explained by parents' social information processing. Depressive symptoms are characteristically accompanied by cognitive distortions or misattributions that have been associated with deleterious parenting strategies such as harsh physical discipline and hostility (Haskett et al. 2003; Leung and Slep 2006; Lorber and O'Leary 2005). The main purpose of this study was to synthesize converging lines of evidence into a testable conceptual model that may explain how parental depression leads to child antisocial behavior via cognitive-behavioral parenting processes (see Fig. 1). In what follows, we review empirical support for hypothesized associations among mothers' and fathers' depressive symptoms, dysfunctional cognitions and physical discipline in light of how these factors become associated with later child conduct problems.

\section{The Association Between Maternal Depressive Symptoms and Parenting}

Major depression, marked by low mood, anhedonia, lethargy and feelings of hopelessness, is the leading cause of disability among women in the world (World Health Organization 2008). The lifetime prevalence rate for major depressive episode is approximately $6 \%$ to $17 \%$ for women (Kessler 2003), with similar rates found among mothers (Somerset et al. 2006). Furthermore, depressive symptoms adversely impacts virtually all domains of parenting and parent-child interactions including social modeling, attachment, monitoring, and discipline (Elgar et al. 2007).

Parenting practices such as harsh discipline may be particularly induced by maternal depressive symptoms. For example, maternal depression has been most strongly associated with negative parenting behaviors that reflect coerciveness and hostility toward the child (e.g., punishment); and only modestly associated with disengaged behaviors such as ignoring, withdrawal, and silence during gaze aversion (Kane and Garber 2004; see Lovejoy et al. 2000 for a review of 46 observational studies).

\section{Depressed Fathers and Parenting}

Depression among men has shown similar patterns of recurrence and persistence as depression among women, occurring about half as often (Kessler 2003). Until recently, research on parental depressive symptoms and most other areas pertinent to child development, has largely neglected fathers (Cassano et al. 2006; Phares et al. 2005). This is 
problematic because fathers make unique and sizeable contributions to children's development. For example, paternal psychopathology has been found to have a comparable risk effect on child and adolescent mental health outcomes as maternal psychopathology. In a meta-analysis encompassing over 100,000 parent-child dyads, paternal and maternal depression had an equivalent modest effect size on child externalizing problems (Connell and Goodman 2002). Furthermore, depressive symptoms in fathers during the postnatal period has been shown to increase risk for hyperactivity and conduct problems in preschoolage children, even after controlling for maternal depressive symptoms and social class (Ramchandani et al. 2005).

Although the effects of paternal depressive symptoms on parenting have not been as well studied as the effects of maternal depressive symptoms, extant evidence suggests that depressed fathers experience similar decreases in parenting competence as mothers with depression. In six cross-sectional studies, paternal depression was associated with heightened father-child conflict (Kane and Garber 2004). Using a community sample, Cummings et al. (2005) showed that fathers who experienced higher levels of depressive symptoms tended to show lower levels of parental warmth and more psychological control (e.g., intrusiveness, use of guilt to control, instilling anxiety) than others. In order to advance our understanding of the association between depressive symptoms and poor parenting, it is critical to examine mechanisms that underlie this association in both mothers and fathers.

\section{Do Negative Appraisals Mediate the Link Between Parental Depressive Symptoms and Ineffective Discipline?}

In classic theories, cognition has been postulated as a key factor in the etiology, maintenance and treatment of depression (Alloy et al. 1988; Beck 1967). Depressotypic cognitions are thought to lead to negatively biased, cynical appraisals of the self and others. In depressed parents, these cognitions may color how they perceive their children (Cummings and Davies 1994). For example, during episodes of parent-child conflict, depressed parents may erroneously interpret their children as having harmful intentions or devious dispositions. These beliefs may prompt frustration, anger or other negative feelings, which in turn may increase the likelihood that parents harshly discipline their children (Ateah and Durrant 2005; Bugental and Happaney 2004).

Dix and Meunier's (2009) action-control model, which is based on social informationprocessing theory (e.g., Crick and Dodge 1994), provides a useful framework for organizing the cognitive mechanisms underlying the association between parental depressive symptoms and parenting practices. A similar framework has been proposed to explain the occurrence of child physical abuse (Bugental 2009; Haskett et al. 2003; Milner 2003). Under the actioncontrol model, a five-step chain of cognitive processes determines parenting behavior: goal processing, input processing, appraisal, emotion activation and response processing. Depressed parents' cognitive appraisals have been studied more than all of the other steps combined (Dix and Meunier 2009), highlighting their salience as proximal influences on parenting behaviors. Across these studies, research has mainly focused on two types of child-related appraisals: faulty attributions about the intentions and causes of children's behavior (i.e., why children misbehave) and global judgments about children's feelings and 
behavior (i.e., how children behave). These appraisals may mediate associations between depressive symptoms and negative parenting practices.

Effective parenting has been linked to appropriate understanding of why children misbehave. For example, mothers who attributed misconduct to causes outside of a child's control, such as fleeting moodiness or immaturity, were much less likely to use physical or harsh discipline than mothers who perceived misbehavior as calculated acts or stable characteristics of the child (Ateah and Durrant 2005; Montes et al. 2001; Snarr et al. 2009). Furthermore, during episodes of child misbehavior, parents with high levels of depressive symptoms have been shown to blame children by attributing negative intentions to them (Bolton et al. 2003; Snarr et al. 2009). Generally, depressed mothers have been found to make more spontaneous and negative causal attributions about their children's behavior problems (e.g., attributing problems as stable, controllable and dispositional child qualities) than mothers who are not depressed (White and Barrowclough 1998).

The associations among depressive symptoms, child-blaming attributions and ineffective discipline suggest a meditational relationship among the three variables. In a community sample of 451 mothers and 449 fathers, parents' child-centered responsibility attributions (e.g., believing that a child's misbehavior is controllable and intentionally harmful) were found to mediate the association between depressive symptoms and overreactive parenting for both mothers and fathers (Leung and Slep 2006). Despite these promising results, other studies have failed to support the meditational role of child-blaming attributions in the relation between parent depressive symptoms and discipline (e.g., Bolton et al. 2003; Slep and O'Leary 2007).

It is also possible that skewed appraisals of how children actually behave (as opposed to why they may behave a certain way) mediate the depression-parenting association. Higher levels of depressive symptoms have been associated with maternal perceptions of infants as less responsive, affectionate, settled, and more difficult (Field et al. 1993). These negative appraisals of children's behavior, like negative attributions about children's intentions and level of control, also have been linked to coercive and insensitive parenting practices (e.g., Lorber and O’Leary 2005).

Although a plethora of evidence has supported the individual components of a meditational relationship among depressive symptoms, appraisal of how children behave, and poor parenting practices, very few investigators have expressly tested for mediation (Dix and Meunier 2009). In one exception, Chi and Hinshaw (2002) found that depression-related distortions about general behavior problems only marginally mediated the positive association between maternal depressive symptoms and negative parenting, such as overuse of power assertion, corporeal punishment, and lack of supervision. Because the Sobel's test did not reach significance in the study, further investigation is needed to establish whether appraisals of child behavior mediate the effect of depressive symptoms on parenting.

\section{Associations Between Physical Punishment and Child Conduct Problems}

Evidence has supported a strong relationship between parents' depressive symptoms and physical punishment. Frequent physical discipline may in turn lead to an array of poor child 
outcomes, including disruptive behavior disorders (Pfiffner et al. 2005). Controlling for sociodemographic variables and dimensions of parental bonding (e.g., parents' protectiveness and authoritarianism), data from the nationally representative National Comorbidity Survey showed that physically punished children were approximately 1.3 times more likely than others to have externalizing problems (Afifi et al. 2006). A meta-analysis of 88 studies conducted by Gershoff (2002) showed that parental corporal punishment was robustly associated with children's short-term and long-term aggression, criminality and antisocial behavior. These associations may not be merely correlative; findings from a genetically informed study with a sample of 887 twin pairs and 2,554 children suggested that harsh forms of physical punishment were causally connected to child externalizing behavior and drug use outcomes (Lynch et al. 2006). Interestingly, observational data from a longitudinal study revealed bidirectional and interactive effects between negative parenting and child externalizing behavior across time (Combs-Ronto et al. 2009).

\section{Current Study}

Ineffective parenting behaviors, such as physical discipline, have been consistently shown to mediate the association between parental depressive symptoms and child externalizing behavior (Burt et al. 2003; Johnson et al. 2006; Elgar et al. 2007; McCarty and McMahon 2003). Yet it remains unclear how depressive symptoms affect parenting practices within this meditational path, especially among fathers. The main aim of this longitudinal study was to explore one of several possible cognitive-behavioral pathways by which risk for externalizing behavior is transmitted from parents with depressive symptoms to their children. Based on Dix and Meunier's (2009) action-control model and the literature on ineffective discipline, we proposed that: (1) depressive symptoms lead to negative appraisals of a child's level of responsiveness and reciprocal affection, (2) which in turn lead to more frequent physical punishment, (3) which in turn predict an increase in subsequent externalizing behavior as rated by multiple informants. Notably, these associations were simultaneously tested in both mothers and fathers.

\section{Method}

\section{Participants}

Participants were 245 children (118 girls) and their parents who took part in an ongoing longitudinal study of young children at risk for school-age conduct problems (MASKED CITATION). Children were approximately 3 years old at Time 1 (T1) and $5 \frac{1}{2} 2$ years old at Time 2 (T2). Families were recruited from local and regional preschool centers, newspaper ads, and pediatrician referrals. Children were recruited at age three to represent the full range of externalizing symptom severity on the Child Behavior Checklist/2-3 (Achenbach 1992), with an over-sampling of young children in the upper range of the Externalizing Problems scale. Twelve children with high familial risk factors (e.g., in initial stages of divorce, facing severe economic hardship), serious chronic health problems, or cognitive impairments (I.Q. <70) were excluded. Families were representative of the local population in a mid-sized city in the Midwestern region of the United States. The majority of children were of European American heritage (86\%), and most others were identified as African American (5\%) or biracial (8\%). Most mothers were married (89\%), 3\% were living with a 
partner, $5 \%$ were single (never married), and $3 \%$ were divorced. The median annual family income was $\$ 52,000$, ranging from $\$ 20,000$ to over $\$ 100,000$.

\section{Procedure}

At T1 and T2, mothers and fathers were interviewed in their homes by a female social worker and then asked to complete a packet of questionnaires. Kindergarten teachers provided ratings of children's behavioral adjustment (T2). Families were paid for their involvement and teachers were given gift certificates for their participation.

\section{Measures}

Parental Depressive Symptoms-Mothers' and fathers' depressive symptoms at T1 were measured by the Depression scale from the Brief Symptom Inventory (BSI; Derogatis 1993). Items were rated on a 5-point Likert scale, characterizing the intensity of symptoms experienced within the previous 7 days. The 6 -item Depression scale ( $\alpha=0.82$ for mothers and 0.77 for fathers) assessed the presence of suicidal thoughts, loneliness, disinterest, sadness, feelings of worthlessness, and hopelessness. This scale has shown good convergent validity and evidence of construct validity (Derogatis and Melisaratos 1983; Morlan and Tan 1998).

Mothers reported an average depression score $(M=0.29, S D=0.44)$ close to the 60th percentile for non-patient women ( $T=52)$, while fathers reported an average depression score $(M=0.24, S D=0.36)$ at the 70th percentile for non-patient men $(T=55)$. Fifteen mothers scored above the 90th percentile ( $T>63,6.2 \%)$. Twenty-three fathers scored in the 90th percentile $(T>63,15 \%)$.

Negative Perceptions of Child Behavior-At T1, mothers and fathers separately rated 11 items from 1 (Strongly Agree) to 5 (Strongly Disagree) pertaining to their attitudes towards their child's level of social responsiveness and rewarding reciprocal affection towards the parent ( $\alpha=0.75$ for mothers and 0.83 for fathers). Six items reflecting perceptions of child unresponsiveness were adapted from the Unresponsiveness scale in the Maternal Perceptions Questionnaire (Olson et al. 1982). Sample items included: "My child seems to prefer spending time by himself/herself rather than with me," and "I wish my child were more affectionate to me." Five items reflecting perceptions of child's lack of affection were taken from the Child Reinforces Parent subscale in the Parenting Stress Index (Abidin 1995). Sample items included: "Sometimes I feel my child doesn't like me and doesn't want to be close to me," and "When I do things for my child I get the feeling that my efforts are not appreciated very much."

Use of Physical Punishment-Dodge et al. (1994) Harshness of Discipline scale was used to assess the frequency of physical punishment during the past 3 months $(0=$ Never, $1=$ Once a month, $2=$ Once a week, $3=$ =Every day, $4=$ Several times a day) for each parent at T1. Physical punishment was defined as spanking, grabbing, or shaking.

Child Externalizing Behavior-At T1, mothers $(n=235)$ and fathers $(n=157)$ completed the Child Behavior Checklist for ages 2-3 (CBCL/2-3; Achenbach 1992). At T2, mothers 
$(n=215)$ and fathers $(n=155)$ completed the CBCL for ages 6-18 (CBCL/6-18; Achenbach and Rescorla 2001). The CBCL is a commonly used rating inventory that measures a child's behavioral and emotional problems based on parents' observations over the previous 2 months. The Externalizing subscale of the CBCL (with subscales in Aggressive Behavior and Destructive Behavior) was used to measure child externalizing behavior.

The Teacher Report Form for ages 6-18 (The TRF/6-18; Achenbach and Rescorla 2001) was completed at T2 by kindergarten teachers $(n=190)$. The TRF and parent CBCL are structurally identical, except that the Externalizing factor subscale consists of Attention Problems (instead of Destructive Behaviors) and Aggressive Behavior. The Externalizing scale was used to create a multi-informant measure of later child externalizing behavior.

At T1, 70 mothers (29\%), 47 fathers (30\%) and 20 preschool teachers (8.3\%) rated children in the borderline clinical range for the Externalizing Problem scale $(T \searrow 60)$. Twenty-eight mothers (11.6\%), 10 fathers (6.4\%), and 14 preschool teachers $(5.8 \%)$ rated children in the clinical range ( $T$ ช64). At T2, 17 mothers (7.1\%), 12 fathers (7.7\%) and 20 teachers (8.3\%) rated children in the borderline clinical range for the Externalizing Problem scale $(T \succeq 6)$. Fourteen mothers (5.8\%), 11 fathers (7\%) and 13 teachers (5.4\%) rated children in the clinical range ( $T \succeq 64)$.

\section{Analysis Plan}

Data Preparation-Structural equation modeling (SEM) was conducted separately for mothers and fathers using AMOS Version 16. Data were checked for extreme outliers and multicollinearity. Evidence of multicollinearity was not found. Approximately 11 cases in mother analyses and 14 cases in father analyses were identified as having multivariate outliers based on a Mahalanobis $D^{2} p$-value cut off of 0.001 . However, these cases were not excluded from analyses in order to reflect the real population distributions of the variables.

Standardized regression coefficients and indices of model fit such as the chi-squared test, comparative fit index (CFI) and root mean square error of approximation (RMSEA) were calculated using maximum likelihood estimation. AMOS requires full data to conduct bootstrapping. Thus, missing data were imputed using maximum likelihood estimation, which is recommended over deletion and single imputation methods insofar as data are missing at random (Schafer and Graham 2002).

Missing data were more of an issue for father variables than mother variables. Data were nearly complete for mother variables (e.g., $\mathrm{T} 1$ variables had no more than $5 \%$ of data missing, and ratings of T2 externalizing behavior were missing for only $12 \%$ of cases). On the other hand, 55\% $(n=135)$ of fathers did not report frequency of physical punishment; between $35 \%$ and $40 \%$ of data were missing for all of the other father variables. In order to determine the appropriateness of data imputation, patterns of missing values were analyzed using Little's MCAR test. Results showed that the data could be assumed to be missing completely at random, $\chi^{2}(568, N=245)=545.61, p>0.7$.

Measurement Model-The measurement model included both mother and father BSI measures of depressive symptoms as indicators of parental depressive symptoms; parent 
ratings of child unresponsiveness and lack of reciprocal affection as indicators of negative perceptions of child behavior; and T2 mother, father and teacher ratings of externalizing behaviors as indicators of later child externalizing behavior. The measurement model fit well, $\chi^{2}(34)=22.20, \mathrm{CFI}=0.98, \mathrm{RMSEA}=0.06$ (90\% CI: 0.02 to 0.10$)$.

Structural Model and Mediation-A structural model containing both mother and father variables was constructed. Mediation was assessed using two converging methods. First, the mediated association between parental depressive symptoms and child externalizing behavior were assessed using the joint significance test (Taylor et al. 2008). The joint significance test provides evidence for mediation insofar as all paths involved in the mediated effect are significantly non-zero. Second, mediation was assessed by bootstrapping (2,000 resamples; Preacher and Hayes 2008) the standardized indirect effects of 1) depressive symptoms on physical punishment, via appraisals of child behavior; 2) appraisals on later externalizing behavior, via physical punishment; as well as 3) depressive symptoms on externalizing behavior, via mediators.

\section{Results}

\section{Descriptive Statistics}

Means, standard deviations and child gender differences for study variables are presented in Table 1. Mother-father differences in study variables within parent pairs were tested using paired samples $t$-tests. Surprisingly, father $(M=0.24, S D=0.36)$ and mother $(M=0.25$, $S D=0.37)$ levels of BSI depressive symptoms did not significantly differ, $t(151)=-1.84, n s$. Mother and father pairs differed on only one study variable: Fathers perceived their child as being less responsive $(M=1.90, S D=0.59)$ than mothers $(M=1.78, S D=0.56), t(151)=-1.99$, $p<0.05$.

Table 2 shows zero-order correlations among study variables included in father and mother models. Note that the table displays correlations among imputed data in order to allow for comparison with the multivariate relationships observed in the structural models. Correlations comparing mother and father variables to one another were also conducted. Mothers' levels of depressive symptoms were positively correlated with fathers' levels, $r=0.17, p<0.01$. Mothers' and fathers' use of physical punishment were also correlated, $r=0.28, p<0.001$.

\section{Association Between Parental Depressive Symptoms and Child Externalizing Behavior}

Holmbeck (1997) recommended that a direct effect model be tested prior to testing a mediation model in SEM. Thus, we simultaneously tested the effect of fathers' and mothers' depressive symptoms on later child externalizing behavior without the inclusion of the cognitive and parenting mediators, $\chi^{2}(4)=7.82, \mathrm{CFI}=0.98$, RMSEA $=0.06$ (90\% CI: $<0.01$ to $0.13)$. Results showed that maternal depressive symptoms predicted higher levels of later child externalizing problems even after controlling for paternal depressive symptoms, $\beta=0.21, p<0.01$. Additionally, paternal depressive symptoms predicted higher levels of externalizing problems, even after accounting for maternal depressive symptoms, $\beta=0.18$, $p=0.01$. 


\section{Mediation Among Mother and Father Variables}

The full structural model showed adequate fit, $\chi^{2}(35)=88.09, \mathrm{CFI}=0.91$, RMSEA $=0.08(90 \%$ CI: 0.06 to 0.10 ). Within the model (Fig. 2), greater maternal depressive symptoms was related to more negative appraisals of their child's behavior, $\beta=0.45, p<0.001$. More negative appraisals of their child's behavior was in turn related to more frequent maternal physical punishment, $\beta=0.20, p<0.05$. More frequent maternal physical punishment predicted higher levels of child externalizing problems at $\mathrm{T} 2, \beta=0.15, p<0.05$. In support of partial mediation, all other structural paths were non-significant, except for the path from maternal appraisals to child externalizing behavior, $\beta=0.48, p<0.001$. These associations held even after controlling for T1 mother- and father-rated externalizing behavior (see Table 3 for information on model fit).

In further support of mediation, maternal depressive symptoms had a significant standardized indirect or mediated effect of 0.09 (bias-corrected 95\% CI: 0.04, 0.17) on maternal physical punishment, via maternal appraisals of child behavior; and negative maternal appraisals had a small, but significant standardized indirect effect of $0.03(0.003$, 0.10 ) on externalizing behavior, via maternal physical punishment. Maternal depressive symptoms had a standardized indirect effect of $0.23(0.13,0.39)$ on later child externalizing behavior, via maternal appraisals and punishment.

As depicted in Fig. 2, greater paternal depressive symptoms was associated with more negative appraisals of their child's level of responsiveness and reciprocal affection, $\beta=0.22$, $p<0.01$. More paternal negative appraisals of child behavior, in turn, predicted more physical punishment, $\beta=0.15, p<0.05$. Finally, more paternal physical punishment predicted greater child externalizing problems, $\beta=0.28, p<0.001$. In support of partial mediation, all non-mediation structural paths were not significant, except for the path from paternal appraisals to child externalizing behavior, $\beta=0.26, p<0.01$. Paternal physical punishment only marginally predicted later externalizing behavior after accounting for $\mathrm{T} 1$ father-rated externalizing problems, $\beta=0.11, p=0.07$; all other paths remained consistent (See Table 3 for model fit information).

In further support of mediation, paternal depressive symptoms had a significant standardized indirect effect of 0.03 (bias-corrected 95\% CI: 0.001, 0.09) on paternal physical punishment, via paternal appraisals of child behavior; and negative paternal appraisals had a significant indirect effect of $0.04(0.002,0.10)$ on externalizing behavior, via paternal physical punishment. Overall, paternal depressive symptoms had a standardized indirect effect of $0.10(0.04,0.18)$ on later child externalizing behavior, via paternal appraisals and punishment.

\section{Predicting Variance in Later Externalizing Behavior}

The full path model shown in Fig. 2 accounted for $51 \%$ of the variance in T2 child externalizing behavior factor. In order to determine the variance explained by maternal factors over and above paternal factors, a nested model was created in which paths from mother variables to child externalizing outcomes were constrained to zero. The variance explained by the constrained model was $30 \%$, indicating that maternal factors explained 
$21 \%$ of the variance in $\mathrm{T} 2$ externalizing behavior. The same procedure was repeated for fathers and revealed that paternal factors alone explained $12 \%$ of the variance in the T2 externalizing behavior, over and above maternal factors.

A second model was run with mother and father ratings of $\mathrm{T} 1$ externalizing problems as covariates, $\chi^{2}(56)=206, \mathrm{CFI}=0.86$, RMSEA $=0.10$ (90\% CI: 0.08 to 0.12$)$. With parenting paths constrained to zero, T1 externalizing ratings explained $54 \%$ of the variance in $\mathrm{T} 2$ externalizing problems. Without the constraints, the model predicted $66 \%$ of the variance in $\mathrm{T} 2$ externalizing problems. Therefore, the parenting variables added $12 \%$ to the prediction of later child externalizing behavior above and beyond $\mathrm{T} 1$ ratings of externalizing. Controlling for $\mathrm{T} 1$ ratings, maternal factors explained $8 \%$ and paternal factors explained $4 \%$ of the variance in $\mathrm{T} 2$ externalizing behavior.

\section{Discussion}

Parenting has been shown to mediate the effect of depressive symptoms on child outcomes (e.g., Burt et al. 2003; Johnson et al. 2006; Elgar et al. 2007; McCarty and McMahon 2003), and in separate studies, distorted cognitions have been shown to mediate the effect of depressive symptoms on parenting (e.g., Chi and Hinshaw 2002; Leung and Slep 2006). To our knowledge, this was the first study to test how relations among parents' depressive symptoms, cognitions and physical discipline longitudinally affected child outcomes under an integrative model. Associations were examined among both mothers and fathers simultaneously, which is rare in research on young children's development (Cassano et al. 2006; Phares et al. 2005).

Structural regression coefficients and bootstrapped indirect effects largely substantiated the proposed mediations for mothers and fathers: Parents' negative perceptions of their child's responsiveness and affection mediated associations between their depressive symptoms and physical punishment. More frequent parental physical punishment during early preschool years, in turn, predicted higher levels of child externalizing problems in kindergarten. In what follows, we elaborate on possible explanations for these findings, and end with a discussion of the study's broader theoretical and clinical implications.

\section{How Do Appraisals of Child Behavior Alter Parenting?}

This study provided support for Dix and Meunier's (2009) action-control theory, which explains how depressive symptoms undermine parenting via skewed cognitive processing. However, because only one type of cognitive mediator was tested, the specific mechanisms linking depressive symptoms and parenting remain an open question. How might appraising a young child as unresponsive and unaffectionate adversely influence discipline in depressed parents? One possible explanation highlights deviations in the development of healthy parent-child relationships. Child responsiveness and affection are rewarding to parents, and thus may play key roles in maintaining healthy parent-child bonds (Abidin 1995). Parents with depressive symptoms may fail to perceive positive bids for attention and therefore be more likely to develop hostile attitudes toward their child, as reflected by harsher discipline toward their child. 
It is normal for young preschoolers to have bouts of defiant, disruptive, oppositional, and aggressive behavior (Earls 1980; Tremblay 2004). Parents who feel insecure or depressed have been found to personalize their child's challenging behaviors (e.g., Bugental 2009). Antagonistic attitudes fostered by these negative appraisals may prime parents to emotionally overreact to common forms of child misbehavior with rash methods such as corporeal punishment (Slep and O'Leary 1998). This problematic process may be further exacerbated in parent-child dyads where the child has a difficult temperament, resulting in a cascade of parent-child conflict (Olson et al. 2002, 2009).

\section{Comparing Fathers and Mothers}

The findings demonstrated that paternal and maternal depressive symptoms, cognitions and physical discipline moderately predicted later child behavioral outcomes, over and above initial severity levels. Consistent with previous research (e.g., Ramchandani et al. 2005), paternal depressive symptoms predicted child conduct problems even after accounting for the effects of maternal depressive symptoms, and vice versa. Fathers' appraisals and behaviors were slightly less influential than mothers' in explaining early child conduct problems, but were important nonetheless. Although mother and father pathways were similar in direction and effect size, fathers' physical discipline only marginally predicted subsequent child externalizing problems after controlling for initial levels of externalizing problems. This suggests that the added predictive validity of paternal physical punishment over current conduct problems may not be as strong as that of maternal physical punishment.

Although the frequency of physical punishment does not significantly differ between mothers and fathers, mothers generally discipline their children more often than fathers, because they spend more time with their children (Hart and Robinson 1994; Nobes et al. 1999; Sandberg and Hofferth 2001). As a result, mothers may have a greater negative influence on their children when they happen to use physical punishment. Indeed, this would also explain why mother variables explained greater variance of later child externalizing behavior compared to father variables.

\section{Strengths and Limitations}

Our study had a number of significant strengths. For example, the study included simultaneous assessments of fathers' depressive symptoms, child-related appraisals, and physical punishment. Fathers were shown to have a significant role on child externalizing outcomes even after accounting for the influence of mothers. As pointed out by several scholars, there continues to be a great need for developmental research on fathers' caregiving behaviors and their long-term consequences (Cassano et al. 2006; Phares et al. 2005).

Stringent handling of the data, and the use of statistical techniques that better model measurement error marked a second set of strengths. Structural equation modeling allowed for estimation of relations with latent variables, thereby minimizing the effects of measurement error. Bootstrapped standardized indirect effects and bias-corrected confidence intervals were included in order to test the hypothesized mediating relationships (Preacher and Hayes 2008). 
Although causality cannot be inferred, stronger inferences about the temporal order and direction of effect of parent factors on child outcomes can be made because child behavior problems were assessed longitudinally 2 years after the parenting variables were assessed. In addition, the possible confounding effect of concurrent problem behavior in predicting later outcomes was minimized by controlling for parents' preschool-age ratings of child externalizing problems in supplementary analyses.

According to the depression $\rightarrow$ distortion hypothesis, the association between depression and child externalizing problems is mostly an artifact of depressed parents' rating errors (Richters 1992). The validity of depressed parents' ratings has been called into question by several studies (Boyle and Pickles 1997; Chi and Hinshaw 2002; Najman et al. 2000). However, we avoided this issue by obtaining ratings of later child externalizing outcomes from multiple informants: mothers, fathers and teachers.

Five main limitations should be noted. First, study participants were drawn from a constrained community sample comprised of mostly middle class, Caucasian, intact families. Thus, results may not generalize to low-income families, parents with clinical levels of depression, or to those with greater levels of ethnic diversity. Second, parent variables (e.g., depressive symptoms, appraisals, and discipline) were concurrently measured, and therefore may not affect one another in the directions specified by the model. Nonetheless, the associations hypothesized by the model made the most sense according to theory (Dix and Meunier 2009). Third, measurements of study variables were somewhat restricted. For example, the measure of corporal punishment did not take severity into account and the measure of depressive symptoms left out key aspects of depression such as chronicity (Brennan et al. 2000). Fourth, about half of the father data were imputed, leading to a potential bias in the results. However, steps were taken to assess that data were missing at random. To further address this limitation, we separately tested the father side of the model using non-imputed data. Results that were consistent with those obtained from imputed data.

Lastly, parents' appraisals of child behavior were assessed using self-report questionnaires. Cognitive appraisals are inherently difficult to assess, and some have contended that selfreports are not sufficient (Bugental et al. 1998; Holden and Edwards 1989). More recently however, others have promoted the use of self-report instruments for measuring parent attributions (Snarr et al. 2009). In future research, investigators should strive to measure a variety of appraisals (e.g., attributions about intentionality, causality, and seriousness of behavior) using multiple methods (observational paradigms and self-reports; e.g., Johnston et al. 2006).

\section{Implications for Research and Practice}

In order to fully appreciate the implications of the study, the model we tested should be considered within the context of the specific developmental time periods examined. The transition from toddlerhood to the preschool-age period may mark a special window of opportunity for studying the associations among parenting processes (Campbell 1995; Olson et al. 2005; Shaw and Bell 1993). During these early years, parents' global attributions and 
disciplinary habits are still forming, as parents adapt to challenges brought by children's burgeoning abilities to have a greater impact on their surroundings.

The preschool years provide an optimal time for examining the effects of depressed parenting on child outcomes, because it is a period in which parents are the primary socializing agents of their children (Campbell et al. 2000). Additionally, depressed parents' negative discipline is typically more pronounced during the early preschool-age period. Parents consider corporal punishment to be most appropriate during the preschool age, and are more apt to resort to physical discipline for preschool-aged children than children who are in infancy or over 5 years old (Gershoff 2002). In future research, it would be fascinating to investigate how associations among parents' depressive symptoms, appraisals and discipline may be differentially related to child conduct problems across diverse periods of development.

While the model under discussion was useful in delineating parent-driven effects on child behavior, future research should encompass transactional models of parent-child socialization processes. Transactional models take into account bidirectional influences of parents and children on one another over time (Sameroff 2009). Albeit more difficult to test, transactional models may be the best way to understand the relationship between parents' depressive symptoms and externalizing psychopathology in children (e.g., Larsson et al. 2008). Child conduct problems may precede the formation of parents' negative appraisals. In a longitudinal study conducted by Snyder et al. (2005), child conduct problems in kindergarten predicted later maternal hostile attributions of child misbehavior and use of ineffective discipline. The idea that consistent exposure to early child externalizing problems shape negative parental attributions has been well supported in other longitudinal studies (e.g., Wilson et al. 2006), as well as studies using observational assessments of attributions (e.g., Johnston et al. 2006).

Given the influence of negative appraisals on the maintenance of ineffective discipline and development of child conduct problems, behavioral parent treatments for child externalizing psychopathology may benefit from including parents' cognitions about their child as targets for change (Johnston et al. 2009; but see Wilson and White 2006 for a discussion of possible exceptions). Incorporating an appraisal-modifying treatment component has met with success in treatments for parents at risk for child maltreatment (Bugental et al. 2002). For example, in a randomized trial of the Triple P-positive parenting program, Sanders et al. (2004) found that parents treated with attributional retraining and anger management showed significantly lower levels of negative parental attributions for children's misbehavior, decreased potential for child abuse and improved (i.e., more realistic) parental expectations than parents who received training in parenting skills alone. This component may be especially important for depressed mothers, because they are more prone to harbor negative appraisals of their children than others. Moreover, children of depressed mothers tend to respond more poorly to behavioral parent treatment than children of non-depressed parents (Beauchaine et al. 2005).

By treating depressed parents when children are young, health professionals may reduce the likelihood of conduct problems emerging. Interventions designed to improve the quality of 
depressed parents' childrearing and parent-child relationships have evinced long-term effectiveness in thwarting negative child outcomes in stages ranging from infancy through adolescence (Beardslee et al. 2007). Treatment benefits may extend well beyond one child's lifetime. Adverse parenting practices, such as harsh discipline, tend to be passed on from generation to generation (Bailey et al. 2009). Hence, successful treatment of one depressed parent may prevent the transmission of deleterious parenting practices for future generations.

\section{Acknowledgments}

This research was supported by a grant from the National Institute of Mental Health (RO1MH57489) to Sheryl Olson and Arnold Sameroff. We are very grateful to the children, parents, teachers, and preschool administrators who participated, and to the many individuals who gave us invaluable help with data collection and coding, especially Gail Benninghoff and Meribeth Gandy Pezda. We also thank the administrators of the University of Michigan Children's Center for their generous assistance.

\section{References}

Abidin, R. Parenting stress index: Professional manual. 3rd ed.. Psychological Assessment Resources; Odessa: 1995.

Achenbach, TM. Manual for child behavior checklist/2-3 and 1992 profile. University of Vermont, Department of Psychiatry; Burlington: 1992.

Achenbach, TM.; Rescorla, LA. Manual for ASEBA school-age forms \& profiles. University of Vermont, Research Center for Children, Youth, \& Families; Burlington: 2001.

Afifi TO, Brownridge DA, Cox BJ, Sareen J. Physical punishment, childhood abuse and psychiatric disorders. Child Abuse \& Neglect. 2006; 30:1093-1103. [PubMed: 17010436]

Alloy L, Abramson L, Metalsky G, Hartlage S. The hopelessness theory of depression: attributional aspects. British Journal of Clinical Psychology. 1988; 27:5-21. [PubMed: 3281732]

Ateah CA, Durrant JE. Maternal use of physical punishment in response to child misbehavior: implications for child abuse prevention. Child Abuse \& Neglect. 2005; 29:169-185. [PubMed: 15734182]

Bailey JA, Hill KG, Oesterle S, Hawkins JD. Parenting practices and problem behavior across three generations: monitoring, harsh discipline, and drug use in the intergenerational transmission of externalizing behavior. Developmental Psychology. 2009; 45:1214-1226. [PubMed: 19702387]

Beardslee W, Wright E, Gladstone T, Forbes P. Long-term effects from a randomized trial of two public health preventive interventions for parental depression. Journal of Family Psychology. 2007; 21:703-713. [PubMed: 18179342]

Beauchaine TP, Webster-Stratton C, Reid MJ. Mediators, moderators, and predictors of 1-year outcomes among children treated for early-onset conduct problems: a latent growth curve analysis. Journal of Consulting and Clinical Psychology. 2005; 73:371-388. [PubMed: 15982136]

Beck, AT. Depression: clinical, experimental, and theoretical aspects. Republished as Depression: Causes and treatment; New York: Hoeber: 1967. Philadelphia: University of Pennsylvania Press

Biederman J, Faraone SV, Hirshfeld-Becker DR, Friedman D, Robin JA, Rosenbaum JF. Patterns of psychopathology and dysfunction in high-risk children of parents with panic disorder and major depression. The American Journal of Psychiatry. 2001; 158:49-57. [PubMed: 11136633]

Bolton C, Calam R, Barrowclough C, Peters S, Roberts J, Wearden A, et al. Expressed emotion, attributions and depression in mothers of children with problem behaviour. Journal of Child Psychology and Psychiatry and Allied Disciplines. 2003; 44:242-254.

Boyle MH, Pickles AR. Influence of maternal depressive symptoms on ratings of childhood behavior. Journal of Abnormal Child Psychology. 1997; 25:399-412. [PubMed: 9421748]

Brennan PA, Hammen C, Andersen MJ, Bor W, Najman JM, Williams GM. Chronicity, severity, and timing of maternal depressive symptoms: relationships with child outcomes at age 5 . Developmental Psychology. 2000; 36:759-766. [PubMed: 11081699] 
Bugental, D. Predicting and preventing child maltreatment: A biocognitive transactional approach. In: Sameroff, AJ., editor. The transactional model of development: How children and contexts shape each other. American Psychological Association; Washington, DC: 2009. p. 97-115.

Bugental D, Ellerson P, Lin EK, Rainey B, Kokotovic A, O'Hara N. A cognitive approach to child abuse prevention. Journal of Family Psychology. 2002; 16:243-258. [PubMed: 12238408]

Bugental DB, Happaney K. Predicting infant maltreatment in low-income families: the interactive effects of maternal attributions and child status at birth. Developmental Psychology. 2004; 40:234-243. [PubMed: 14979763]

Bugental DB, Johnston C, New M, Silvester J. Measuring parental attributions: conceptual and methodological issues. Journal of Family Psychology. 1998; 12:459-480.

Burt SA, Krueger RF, McGue M, Iacono W. Parent-child conflict and the comorbidity among childhood externalizing disorders. Archives of General Psychiatry. 2003; 60:505-513. [PubMed: 12742872]

Campbell S. Behavior problems in preschool children: a review of recent research. Journal of Child Psychology and Psychiatry. 1995; 36:113-149. [PubMed: 7714027]

Campbell S, Shaw D, Gilliom M. Early externalizing behavior problems: toddlers and preschoolers at risk for later maladjustment. Development and Psychopathology. 2000; 12:467-488. [PubMed: 11014748]

Cassano M, Adrian M, Veits G, Zeman J. The inclusion of fathers in the empirical investigation of child psychopathology: an update. Journal of Clinical Child and Adolescent Psychology. 2006; 35:583-589. [PubMed: 17007604]

Chi TC, Hinshaw SP. Mother-child relationships of children with ADHD: the role of maternal depressive symptoms and depression-related distortions. Journal of Abnormal Child Psychology. 2002; 30:387-400. [PubMed: 12109489]

Combs-Ronto LA, Olson SL, Lunkenheimer ES, Sameroff AJ. Interactions between maternal parenting and children's early disruptive behavior: bidirectional associations across the transition from preschool to school entry. Journal of Abnormal Child Psychology. 2009; 37:1151-1163. [PubMed: 19533326]

Connell AM, Goodman SH. The association between psychopathology in fathers versus mothers and children's internalizing and externalizing behavior problems: a meta-analysis. Psychological Bulletin. 2002; 128:746-773. [PubMed: 12206193]

Crick NR, Dodge KA. A review and reformulation of social information-processing mechanisms in children's social adjustment. Psychological Bulletin. 1994; 115:74-101.

Cummings EM, Davies PT. Maternal depression and child development. Journal of Child Psychology and Psychiatry and Allied Disciplines. 1994; 35:73-112.

Cummings EM, Keller PS, Davies PT. Towards a family process model of maternal and paternal depressive symptoms: exploring multiple relations with child and family functioning. Journal of Child Psychology and Psychiatry. 2005; 46:479-489. [PubMed: 15845128]

Derogatis, LR. Brief symptom inventory: Administration, scoring, and procedures manual. National Computer Systems, Inc.; Minneapolis: 1993.

Derogatis L, Melisaratos N. The Brief Symptom Inventory: An introductory report. Psychological Medicine: A Journal of Research in Psychiatry and the Allied Sciences. 1983; 13:595-605.

Dix T, Meunier LN. Depressive symptoms and parenting competence: an analysis of 13 regulatory processes. Developmental Review. 2009; 29:45-68.

Dodge KA, Pettit GS, Bates JE. Socialization mediators of the relation between socioeconomic status and child conduct problems. Child Development. 1994; 65:649-665. [PubMed: 8013245]

Earls F. Prevalence of behavior problems in 3-year-old children: a cross-national replication. Archives of General Psychiatry. 1980; 37:1153-1157. [PubMed: 7425799]

Elgar FJ, Mills RSL, McGrath PJ, Waschbusch DA, Brownridge DA. Maternal and paternal depressive symptoms and child maladjustment: the mediating role of parental behavior. Journal of Abnormal Child Psychology. 2007; 35:943-955. [PubMed: 17577659]

Field T, Morrow C, Adlestein D. Depressed mothers' perceptions of infant behavior. Infant Behavior \& Development. 1993; 16:99-108. 
Gershoff ET. Corporal punishment by parents and associated child behaviors and experiences: a metaanalytic and theoretical review. Psychological Bulletin. 2002; 128:539-579. [PubMed: 12081081]

Goodman SH. Depression in mothers. Annual Review of Clinical Psychology. 2007; 3:107-135.

Goodman SH, Gotlib IH. Risk for psychopathology in the children of depressed mothers: a developmental model for understanding mechanisms of transmission. Psychological Review. 1999; 106:458-490. [PubMed: 10467895]

Hart CH, Robinson CC. Comparative study of maternal and paternal disciplinary strategies. Psychological Reports. 1994; 74:495-498. [PubMed: 8197287]

Haskett ME, Scott SS, Grant R, Ward CS, Robinson C. Child-related cognitions and affective functioning of physically abusive and comparison parents. Child Abuse \& Neglect. 2003; 27:663686. [PubMed: 12818613]

Holden GW, Edwards LA. Parental attitudes toward child rearing: instruments, issues, and implications. Psychological Bulletin. 1989; 106:29-58.

Holmbeck G. Toward terminological, conceptual, and statistical clarity in the study of mediators and moderators: Examples from the child-clinical and pediatric psychology literatures. Journal of Consulting and Clinical Psychology. 1997; 65:599-610. [PubMed: 9256561]

Johnson JG, Cohen P, Chen HN, Kasen S, Brook JS. Parenting behaviors associated with risk for offspring personality disorder during adulthood. Archives of General Psychiatry. 2006; 63:579_ 587. [PubMed: 16651515]

Johnston C, Chen M, Ohan J. Mothers' attributions for behavior in nonproblem boys, boys with attention deficit hyperactivity disorder, and boys with attention deficit hyperactivity disorder and oppositional defiant behavior. Journal of Clinical Child and Adolescent Psychology. 2006; 35:60 71. [PubMed: 16390303]

Johnston C, Hommersen P, Seipp C. Maternal attributions and child oppositional behavior: a longitudinal study of boys with and without attention-deficit/hyperactivity disorder. Journal of Consulting and Clinical Psychology. 2009; 77:189-195. [PubMed: 19170464]

Kane P, Garber J. The relations among depression in fathers, children's psychopathology, and fatherchild conflict: a meta-analysis. Clinical Psychology Review. 2004; 24:339-360. [PubMed: 15245835]

Kendziora K, O'Leary S. Dysfunctional parenting as a focus for prevention and treatment of child behavior problems. Advances in Clinical Child Psychology. 1993; 15:175-206.

Kessler RC. Epidemiology of women and depression. Journal of Affective Disorders. 2003; 74:5-13. [PubMed: 12646294]

Kim-Cohen J, Moffitt TE, Taylor A, Pawlby SJ, Caspi A. Maternal depression and children's antisocial behavior: nature and nurture effects. Archives of General Psychiatry. 2005; 62:173-181. [PubMed: 15699294]

Larsson H, Viding E, Rijsdijk FV, Plomin R. Relationships between parental negativity and childhood antisocial behavior over time: a bidirectional effects model in a longitudinal genetically informative design. Journal of Abnormal Child Psychology. 2008; 36:633-645. [PubMed: 17602294]

Leung DW, Slep AMS. Predicting inept discipline: the role of parental depressive symptoms, anger, and attributions. Journal of Consulting and Clinical Psychology. 2006; 74:524-534. [PubMed: 16822109]

Lorber MF, O'Leary SG. Mediated paths to overreactive discipline: mothers' experienced emotion, appraisals, and physiological responses. Journal of Consulting and Clinical Psychology. 2005; 73:972-981. [PubMed: 16287397]

Lovejoy MC, Graczyk PA, O’Hare E, Neuman G. Maternal depression and parenting behavior: a meta-analytic review. Clinical Psychology Review. 2000; 20:561-592. [PubMed: 10860167]

Luoma I, Tamminen T, Kaukonen P, Laippala P, Puura K, Salmelin R, et al. Longitudinal study of maternal depressive symptoms and child well-being. Journal of the American Academy of Child and Adolescent Psychiatry. 2001; 40:1367-1374. [PubMed: 11765281]

Lynch SK, Turkheimer E, D’Onofrio BM, Mendle J, Emery RE, Slutske WS, et al. A genetically informed study of the association between harsh punishment and offspring behavioral problems. Journal of Family Psychology. 2006; 20:190-198. [PubMed: 16756394] 
McCarty CA, McMahon RJ. Mediators of the relation between maternal depressive symptoms and child internalizing and disruptive behavior disorders. Journal of Family Psychology. 2003; 17:545-556. [PubMed: 14640804]

Milner JS. Social information processing in high-risk and physically abusive parents. Child Abuse \& Neglect. 2003; 27:7-20. [PubMed: 12510028]

Montes MP, de Paul J, Milner JS. Evaluations, attributions, affect, and disciplinary choices in mothers at high and low risk for child physical abuse. Child Abuse \& Neglect. 2001; 25:1015-1036. [PubMed: 11601595]

Morlan K, Tan S. Comparison of the brief psychiatric rating scale and the brief symptom inventory. Journal of Clinical Psychology. 1998; 54:885-894. [PubMed: 9811126]

Najman JM, Williams GM, Nikles J, Spence S, Bor W, O'Callaghan M, et al. Mothers' mental illness and child behavior problems: cause-effect association or observation bias? Journal of the American Academy of Child and Adolescent Psychiatry. 2000; 39:592-602. [PubMed: 10802977]

Nobes G, Smith M, Upton P, Heverin A. Physical punishment by mothers and fathers in British homes. Journal of Interpersonal Violence. 1999; 14:887-902.

Olson SL, Bates JE, Bayles K. Maternal perceptions of infant and toddler behavior: a longitudinal, construct validation study. Infant Behavior \& Development. 1982; 5:397-410.

Olson SL, Bates JE, Sandy JM, Schilling EM. Early developmental precursors of impulsive and inattentive behavior: from infancy to middle childhood. Journal of Child Psychology and Psychiatry. 2002; 43:435-447. [PubMed: 12030590]

Olson S, Sameroff A, Kerr D, Lopez N, Wellman H. Developmental foundations of externalizing problems in young children: the role of effortful control. Development and Psychopathology. 2005; 17:25-45. [PubMed: 15971758]

Olson, S.; Sameroff, A.; Lunkenheimer, E.; Kerr, D. Biopsychosocial regulatory processes in the development of childhood behavioral problems. Cambridge University Press; New York, NY US: 2009. Self-regulatory processes in the development of disruptive behavior problems: the preschool-to-school transition; p. 144-185.

Pfiffner L, McBurnett K, Rathouz P, Judice S. Family correlates of oppositional and conduct disorders in children with attention deficit/hyperactivity disorder. Journal of Abnormal Child Psychology. 2005; 33:551-563. [PubMed: 16195950]

Phares V, Lopez E, Fields S, Kamboukos D, Duhig AM. Are fathers involved in pediatric psychology research and treatment? Journal of Pediatric Psychology. 2005; 30:631-643. [PubMed: 15772363]

Preacher KJ, Hayes AF. Asymptotic and resampling strategies for assessing and comparing indirect effects in multiple mediator models. Behavior Research Methods. 2008; 40:879-891. [PubMed: 18697684]

Ramchandani P, Stein A, Evans J, O'Connor TG, Team AS. Paternal depression in the postnatal period and child development: a prospective population study. Lancet. 2005; 365:2201-2205. [PubMed: 15978928]

Richters JE. Depressed mothers as informants about their children: a critical review of the evidence for distortion. Psychological Bulletin. 1992; 112:485-499. [PubMed: 1438639]

Riggins-Caspers KM, Cadoret RJ, Knutson JF, Langbehn D. Biology-environment interaction and evocative biology-environment correlation: contributions of harsh discipline and parental psychopathology to problem adolescent behaviors. Behavior Genetics. 2003; 33:205-220. [PubMed: 12837013]

Sameroff, AJ., editor. The transactional model of development: How children and contexts shape each other. American Psychological Association; Washington, DC: 2009.

Sandberg JF, Hofferth SL. Changes in children's time with parents: United States, 1981-1997. Demography. 2001; 38:423-436. [PubMed: 11523269]

Sanders MR, Pidgeon AM, Gravestock F, Connors MD, Brown S, Young RW. Does parental attributional retraining and anger management enhance the effects of the triple P-positive parenting program with parents at risk of child maltreatment? Behavior Therapy. 2004; 35:513535.

Schafer JL, Graham JW. Missing data: our view of the state of the art. Psychological Methods. 2002; 7:147-177. [PubMed: 12090408] 
Shaw D, Bell R. Developmental theories of parental contributors to antisocial behavior. Journal of Abnormal Child Psychology. 1993; 21:493-518. [PubMed: 8294650]

Slep AMS, O'Leary SG. The effects of maternal attributions on parenting: an experimental analysis. Journal of Family Psychology. 1998; 12:234-243.

Slep A, O'Leary S. Multivariate models of mothers' and fathers' aggression toward their children. Journal of Consulting and Clinical Psychology. 2007; 75:739-751. [PubMed: 17907856]

Snarr JD, Slep AMS, Grande VP. Validation of a new self-report measure of parental attributions. Psychological Assessment. 2009; 21:390-401. [PubMed: 19719350]

Snyder J, Cramer A, Afrank J, Patterson GR. The contributions of ineffective discipline and parental hostile attributions of child misbehavior to the development of conduct problems at home and school. Developmental Psychology. 2005; 41:30-41. [PubMed: 15656735]

Somerset, W.; Newport, DJ.; Ragan, K.; Stowe, ZN. Depressive disorders in women: From menarche to beyond the menopause. In: Keyes, CLM.; Goodman, SH., editors. Women and depression: A handbook for the social, behavioral, and biomedical sciences. Cambridge University Press; New York: 2006. p. 62-88.

Taylor AB, MacKinnon DP, Tein JY. Tests of the three-path mediated effect. Organizational Research Methods. 2008; 11:241-269.

Tremblay, RE. The development of human physical aggression: How important is early childhood?. In: Leavitt, LA.; Hall, DMB., editors. Social and moral development: Emerging evidence on the toddler years. Johnson \& Johnson Pediatric Institute; Brunswick: 2004. p. 221-238.

Webster-Stratton C, Hammond M. Maternal depression and its relationship to life stress, perceptions of child behavior problems, parenting behaviors, and child conduct problems. Journal of Abnormal Child Psychology. 1988; 16:299-315. [PubMed: 3403812]

White C, Barrowclough C. Depressed and non-depressed mothers with problematic preschoolers: attributions for child behaviours. British Journal of Clinical Psychology. 1998; 37:385-398. [PubMed: 9856292]

Wilson C, Gardner F, Burton J, Leung S. Maternal attributions and young children's conduct problems: a longitudinal study. Infant and Child Development. 2006; 15:109-121.

Wilson C, White C. A preliminary investigation of the effect of intervention on parental attributions and reported behaviour. Behavioural and Cognitive Psychotherapy. 2006; 34:503-507.

World Health Organization. The global burden of disease: 2004 update. Author; Geneva: 2008. 


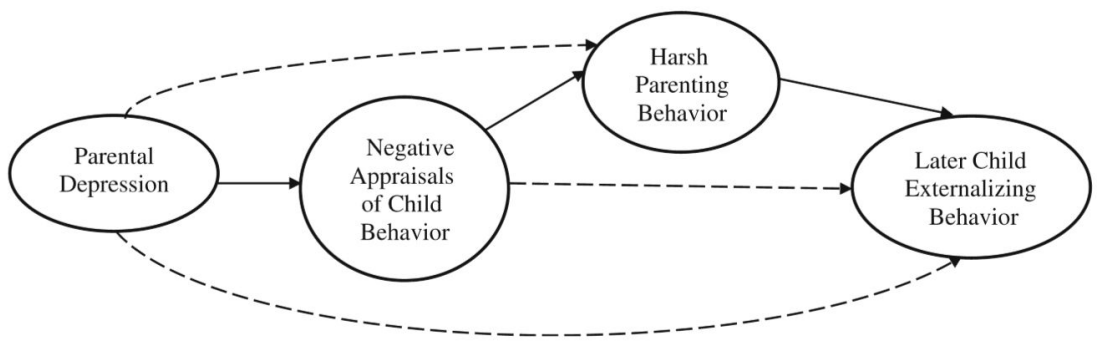

Fig. 1.

Proposed conceptual model: the effect of parental depression on later child externalizing behavior via child-related cognitions and physical punishment. Dashed lines represent paths that may be explained by factors external to the model 


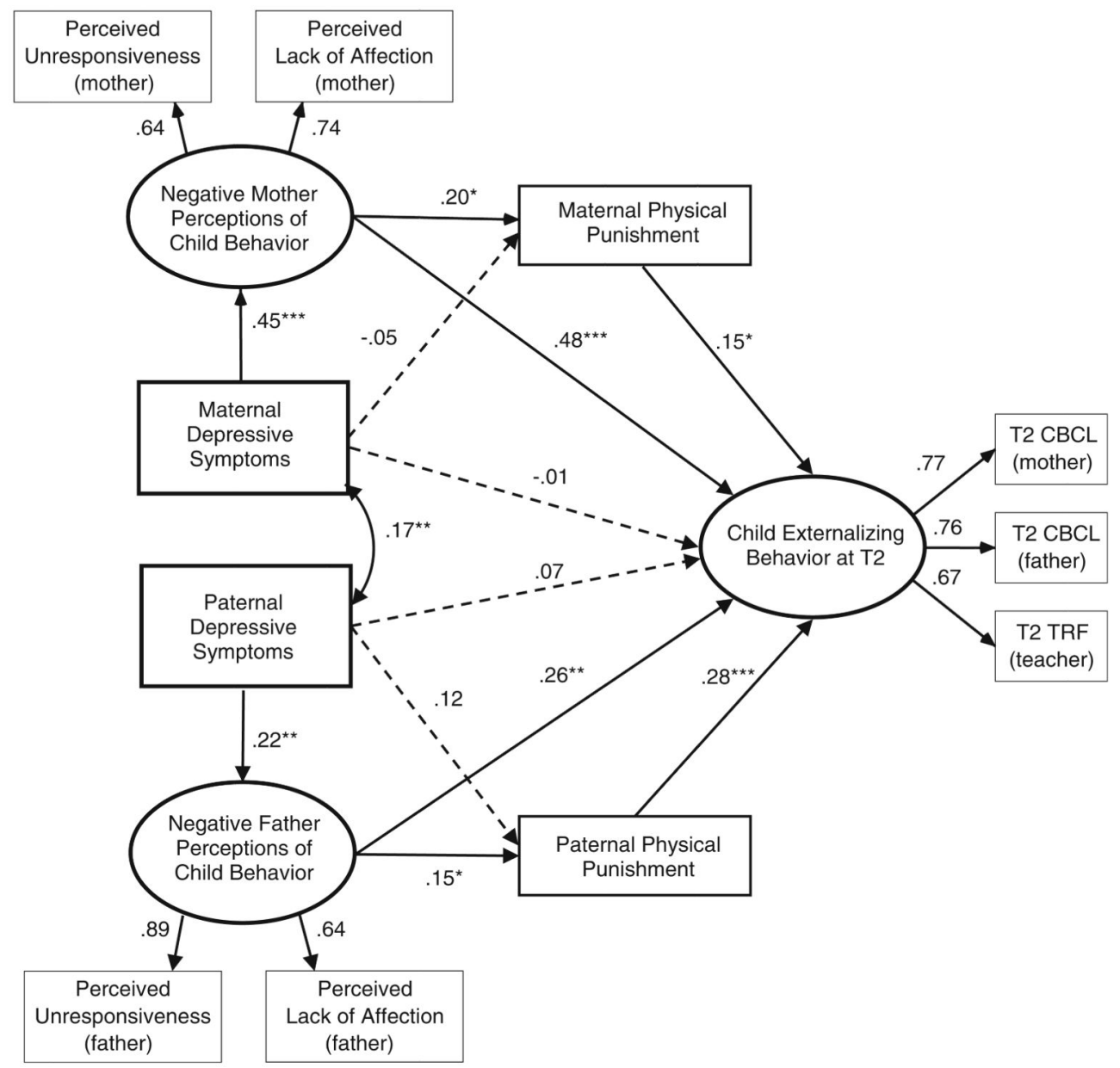

Fig. 2.

Full structural model of the effects of maternal and paternal depressive symptoms on later child externalizing behavior via appraisals and parenting practices. Numbers on structural paths represent standardized regression coefficients. Dashed lines indicate non-significant effects. $* p<0.05$. $* * p<0.01$. $* * * p<0.001$ 
Table 1

Means and standard deviations of non-imputed study variables

\begin{tabular}{|c|c|c|c|c|c|}
\hline & \multicolumn{2}{|l|}{$\underline{M}$} & \multicolumn{2}{|l|}{$\underline{S D}$} & \multirow[t]{2}{*}{ Gender Differences } \\
\hline & Boys & Girls & Boys & Girls & \\
\hline \multicolumn{6}{|l|}{ Parental depressive symptoms } \\
\hline BSI maternal depression & 0.24 & 0.35 & 0.37 & 0.50 & $\mathrm{G}>\mathrm{B}, p<0.10$ \\
\hline BSI paternal depression & 0.23 & 0.25 & 0.35 & 0.37 & \\
\hline \multicolumn{6}{|l|}{ Parent appraisals of child behavior } \\
\hline Unresponsiveness (mother-rated) & 1.76 & 1.78 & 0.51 & 0.54 & \\
\hline Lack of affection (mother-rated) & 1.83 & 1.80 & 0.55 & 0.60 & \\
\hline Unresponsiveness (father-rated) & 1.91 & 1.90 & 0.61 & 0.56 & \\
\hline Lack of affection (father-rated) & 1.93 & 1.83 & 0.62 & 0.61 & \\
\hline \multicolumn{6}{|l|}{ Parent discipline } \\
\hline Maternal physical punishment & 1.18 & 0.94 & 0.94 & 0.80 & $\mathrm{~B}>\mathrm{G}, p<0.05$ \\
\hline Paternal physical punishment & 1.07 & 0.81 & 0.92 & 0.87 & \\
\hline \multicolumn{6}{|l|}{ Child externalizing behavior } \\
\hline T1 CBCL externalizing (mother) & 11.84 & 11.17 & 7.37 & 7.27 & $\mathrm{~B}>\mathrm{G}, p<0.05$ \\
\hline T1 CBCL externalizing (father) & 11.72 & 9.57 & 7.08 & 6.06 & \\
\hline T2 CBCL externalizing (mother) & 7.25 & 5.98 & 6.69 & 5.10 & \\
\hline T2 CBCL externalizing (father) & 6.59 & 5.06 & 5.68 & 4.85 & $\mathrm{~B}>\mathrm{G}, p<0.10$ \\
\hline T2 TRF externalizing (teacher) & 5.59 & 3.09 & 9.10 & 6.65 & $\mathrm{~B}>\mathrm{G}, p<0.05$ \\
\hline
\end{tabular}




\section{Table 2}

Correlations among parental depression, appraisals, discipline, and child externalizing behavior

\begin{tabular}{lllllllll}
\hline & $\mathbf{1}$ & $\mathbf{2}$ & $\mathbf{3}$ & $\mathbf{4}$ & $\mathbf{5}$ & $\mathbf{6}$ & $\mathbf{7}$ & $\mathbf{8}$ \\
\hline (1) BSI depression & - & $0.21^{* * *}$ & $0.39^{* * *}$ & 0.08 & $0.33^{* * *}$ & $0.22^{* * *}$ & $0.18^{* *}$ & 0.11 \\
(2) Perceived unresponsiveness & $0.19^{* *}$ & - & $0.47^{* * *}$ & $0.25^{* * *}$ & $0.47^{* * *}$ & $0.37^{* * *}$ & $0.37^{* * *}$ & $0.27^{* * *}$ \\
(3) Perceived lack of affection & $0.18^{* *}$ & $0.57^{* * *}$ & - & $0.21^{* * *}$ & $0.47^{* * *}$ & $0.35^{* * *}$ & $0.35^{* * *}$ & $0.16^{*}$ \\
(4) Physical punishment & $0.17^{* *}$ & $0.16^{*}$ & $0.15^{*}$ & - & $0.26^{* * *}$ & $0.30^{* * *}$ & $0.21^{* * *}$ & $0.23^{* * *}$ \\
(5) T1 CBCL EXT & $0.17^{* *}$ & $0.36^{* * *}$ & $0.34^{* * *}$ & $0.45^{* * *}$ & - & $0.52^{* * *}$ & $0.40^{* * *}$ & $0.28^{* * *}$ \\
(6) T2 CBCL EXT (mother) & $0.16^{*}$ & $0.31^{* * *}$ & 0.09 & $0.24^{* * *}$ & $0.48^{* * *}$ & - & $0.59^{* * *}$ & $0.55^{* * *}$ \\
(7) T2 CBCL EXT (father) & $0.28^{* * *}$ & $0.31^{* * *}$ & $0.26^{* * *}$ & $0.46^{* * *}$ & $0.72^{* * *}$ & $0.58^{* * *}$ & - & $0.50^{* * *}$ \\
(8) T2 TRF EXT (teacher) & 0.10 & $0.22^{* * *}$ & $0.14^{*}$ & $0.36^{* * *}$ & $0.49^{* * *}$ & $0.54^{* * *}$ & $0.60^{* * *}$ & - \\
\hline
\end{tabular}

Correlations of imputed data used for SEM are reported. $N=245$ for all variables. Values above the diagonal show correlations among mother-rated variables; values below the diagonal show correlations among father-rated variables. Variables 8, 9, and 10 were rated by mothers, fathers and teachers, respectively

* $p<0.05$.

$* *$

$p<0.01$.

$* * *$

$p<0.001$ 
Table 3

Fit indices for models assessed in the study

\begin{tabular}{llllll}
\hline Model & $\chi^{2}$ & $d f$ & CFI & RMSEA (90\% CI $)$ & AIC \\
\hline Measurement model & $22.20^{*}$ & 11 & 0.98 & $0.06(0.02$ to 0.10$)$ & 70.20 \\
Direct effects model & 7.82 & 4 & 0.98 & $0.06(<0.001$ to 0.13$)$ & 39.82 \\
Full mediation model & $88.09^{* * *}$ & 35 & 0.91 & $0.08(0.06$ to 0.10$)$ & 172.09 \\
Full model with T1 EXT & $206^{* * *}$ & 56 & 0.86 & $0.10(0.08,0.12)$ & 283.58 \\
\hline
\end{tabular}

$N s=245$ mothers and 245 fathers. $\chi^{2}=$ chi-square goodness-of-fit statistic; $C F I$ comparative fit index; CFI $>0.90$ conventionally indicates acceptable model fit. RMSEA root mean square error of approximation; RMSEA<0.06 indicates adequate fit. AIC Akaike's information criterion; smaller AIC values indicate better relative fit

* $p<0.05$.

$* *$

$p<0.01$

$* * *$

$p<0.001$ 